\title{
A Survey of Infringements of Gricean Maxims in Some Precautionary Inscriptions on Medicine Packets
}

\author{
Rosarri C. Mbisike ${ }^{* 1}$ \\ Department of English, Faculty of Arts, Lagos State University, Lagos, Nigeria
}

*Corresponding Author

Email: rozchin2005@yahoo.com

DOI: http://dx.doi.org/10.18326/jopr.v3i2.160-172

Copyright (C) the Author (s)

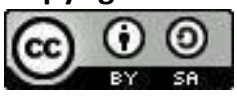

This work is licensed under a Creative Commons Attribution-ShareAlike 4.0 International License.

How to Cite: Mbisike, R. C. (2021). A Survey of Infringements of Gricean Maxims in Some Precautionary Inscriptions on Medicine Packets. Journal of Pragmatics Research, 3(2). doi: http://dx.doi.org/10.18326/jopr.v3i2.160-172

\author{
Submission \\ Track: \\ Received: 04-08- \\ 2021 Final Revision: \\ 04-09-2021 Available \\ online: 06-09-2021 \\ Corresponding \\ Author: \\ Rosarri C. Mbisike \\ rozchin2005@yahoo.com
}

\begin{abstract}
In communication, participants are expected to cooperate through observing a set of maxims. Nevertheless, some communicative instances reveal that there are cases of unintentional non-observance of the maxims, which Grice (1975) categorized as "infringing a maxim". These instances of infringements call for attention to the extent that they could cause breakdown in communication. In this regard, the aim of this paper is to investigate some cases of infringements of the maxims in selected precautionary inscriptions on some medicine packets, with the objective to examine how such messages are interpreted. The theoretical framework adopted for this research is based on Gricean pragmatics. The method for this research is qualitative and its paradigm is interpretive. The data were collected from some packets of medicine sold in some pharmacy shops in Lagos, Nigeria. One of the major observations made in the course of this research is that, out of the four classes of the Gricean maxims, only the maxim of quality was not infringed in any precautionary inscription in the data. This result may be justified by the reason that precautionary inscriptions on medicine packets should be carefully couched in truth, so as not to jeopardize the health of the patients. Further studies on various cases of infringements in diverse aspects of communication are strongly recommended.
\end{abstract}

Keywords: Precautionary Inscriptions; Communication; Pragmatics; Maxims; Infringements

\section{INTRODUCTION}

The notion of interpretation is vital to comprehension of messages. Essentially, the interpretation of utterances involves making the right inferences and appropriate assumptions. It is only when utterances are correctly interpreted that communication can be successful. In this 
connection, the relevance of accurate interpretation of precautionary inscriptions on medicine packets cannot be overemphasized, particularly being that drugs must be handled with absolute caution, to get the right results, as well as prevent mishaps.

Interestingly, earlier studies on medicine information leaflets had been focused on evaluating the informative values the leaflets convey (Griffin and Griffin, 1996); establishing readability of the leaflets (Bradley et. al, 1994, Auta et. al, 2011); and examining the discourse forms and functions contained in the medicine leaflets (Yusuf and Odebunmi, 2011). Generally, these studies emphasized the need for effective communication in conveying medicine information.

As noted by Grice (1975), participants are expected to cooperate in communication, through observing a set of maxims, which he categorized as: maxim of quantity, maxim of quality, maxim of relation, and maxim of manner. However, there are many occasions in which participants fail to observe the maxims, through different ways as noted by Grice (1975), which could be by flouting a maxim, violating a maxim, opting out of a maxim, or infringing a maxim. Of these types of non-observance of the maxims, 'flouting a maxim', which is an intentional type that generates implicatures, has been the dominant type that has occupied the works of several researchers in the field of pragmatics.

Nevertheless, some communicative instances reveal that there are cases of unintentional non-observance of the maxims, which Grice (1975) categorized as "infringing a maxim". These instances of infringements call for attention to the extent that they could lead to a breakdown in communication. In this regard, the focus of this study is directed at the precautionary inscriptions on medicine packets, with the aim to investigate some cases of infringements of the maxims, which pose problems with correct interpretation of the inscriptions. Essentially, in order to prevent problems that may arise from wrong interpretation of precautionary inscriptions on medicine packets, it is vital to investigate the level of information contained in some precautionary inscriptions on medicine packets, with the objective to examine instances of infringements of the Gricean maxims contained in the precautionary inscriptions, and also determine how such messages could be interpreted correctly.

The theoretical framework adopted for the analysis of infringed maxims contained in the precautionary inscriptions is hinged on the Gricean notion of pragmatics. Pragmatics deals with the study of language in use. [See, Stalnaker (1972), Kempson (1975), and Levinson (1983).] In other words, pragmatics is concerned with the study of language in relation with the context of performance. Mey (2001:6) notes that:

Communication in society happens chiefly by means of language. However, the users of language, as social beings, communicate and use language on society's premises; society controls their access to the linguistic and communicative means. Pragmatics, as the study of 
the way humans use their language in communication, bases itself on a study of those premises and determines how they affect, and effectualize, human language use. Hence: Pragmatics studies the use of language in human communication as determined by the conditions of society.

Invariably, pragmatics deals with utterance interpretation within a particular context. Sperber and Wilson (1981:28) point out that "an adequate pragmatic theory should incorporate a general account of the processing of conceptual information in a context, and a particular account of whatever special principles and problems are involved in the processing of information that has been intentionally, and linguistically, communicated." This proposition is based on the theory put forward by H.P. Grice (1975), in which he points out that in all communication there is a general agreement of cooperation between a speaker and a hearer, which he called the Cooperative Principle (CP). [See, Kempson (1977), Leech (1983), Levinson (1983), Thomas (1995), Yule (1996), Verschueren (1999), Mey (2001), Mbisike (2001), Huang (2007), Akmajian et. al. (2012).]

\section{The Cooperative Principle}

The Cooperative Principle, propounded by Grice (1975), provides us with a framework within which we derive an explanation of how speakers succeed in using sentences(s) of language to communicate information that is unspecified by the literal meaning of the sentence(s) in question. The cooperative principle subsumes a set of maxims that specify the conventions that should govern participants in a conversation. The maxims, in other words, represent an attempt to account for how conversations are construed by participants in different speech situations. The maxims are thus presented as follows:

\section{Maxim of Quantity:}

Make your contribution as informative as is required (for the current purposes of the exchange). In other words, do not make your contribution more informative than is required.

\section{Maxim of Quality:}

Do not say what you believe to be false. This is to say that you should not say that for which you lack adequate evidence.

\section{Maxim of Relation:}

Be relevant. Let your message be well related to, or connected with, the topic of discourse.

\section{Maxim of Manner:}

Be perspicuous. Thus, let your message be clear by avoiding obscurity and by avoiding ambiguity. As much as possible, make your message brief, as well as orderly.

The above maxims show that the cooperative principle suggests that communication is essentially a co-operative endeavor governed by specifiable conventions. However, unlike 
linguistic rules, the maxims are often not observed. For instance, many people tell lies and some people make irrelevant statements. Moreover, speakers sometimes break these rules (maxims) deliberately and blatantly in order to convey some extra information that is in accordance along with the cooperative principle and which they assume that the hearers can work out. This extra information is what Grice called conversational implicature. [See, Kempson (1977), Levinson (1983), Thomas (1995), Verschueren (1999), Mey (2001), Mbisike (2001), Huang (2007), Akmajian et. al. (2012).] In essence, this non-observance of the maxims calls for further discussion, as presented below.

\section{Non-Observance of the Maxims}

Grice (1975) points out that there are several circumstances when people fail to observe the maxims. He notes four ways of failing to observe a maxim: flouting a maxim, violating a maxim, opting out of a maxim, and infringing a maxim. However, some linguists added a fifth way of failing to observe the maxims, namely, suspending a maxim. [See, Keenan (1976), Thomas (1995).] Each of these cases of non-observance of the maxims is discussed below.

\section{Flouting a Maxim}

Grice (1975) notes that a 'flout' occurs when a speaker blatantly fails to observe a maxim in his utterance, with the deliberate intention to prompt the hearer to work out a meaning which is different from, or an extra meaning to, the expressed meaning, thereby, generating an implicature. Thus, flouting a maxim generates an additional meaning called an implicature. Grice (1975) classified implicature into two types, namely, conventional implicature and conversational implicature. [See, Kempson (1977), Sadock (1978), Levinson (1983), Thomas (1995), Yule (1996), Verschueren (1999), Mey (2001), Mbisike (2001), Huang (2007), Akmajian et. al. (2012).]

Thus, a speaker flouts the maxims of quantity by blatantly providing either more or less information than is required for the situation. Moreover, in the case of flouting the maxim of quality, the speaker conveys a message which is blatantly untrue, or for which he or she lacks adequate evidence. In the same vein, the maxim of relation ('be relevant') is flouted by putting up a response that is out-rightly unrelated to the topic of discourse. In addition, the maxim of manner is flouted by failing to be clear, lack of brevity as required, and lack of order. However, being that the interlocutors operate on the belief that, as a rule, the maxims will be observed, it is important to note that in each of the cases of flouting a maxim; it is the obvious breaking of a maxim that prompts the deductive process of working out an implicature. Consider the following example: John is a lion. This utterance flouts the maxim of quality by expressing an untruth, but on the contrary, the speaker implies something that is true. It is a metaphorical expression and it involves a non-linguistic knowledge of the world for the hearer to interpret it. 
Grice's 'implicature' provides us with a natural explanation of the interpretation of metaphor. In order to interpret this utterance in accordance with the Cooperative Principle, the hearer must assume that the speaker is conveying extra information other than the literal meaning of the sentence. Definitely, the speaker is not saying that 'John' is an animal, rather, since 'lion' is a large, strong and courageous animal, called 'the King of Beasts', the hearer will then deduce that the speaker implies that 'John is a very brave man'; which is the conversational implicature of the utterance. Thus, the concept of implicature provides us with an explanation of utterance interpretation. This interpretation was realized based on the assumption that in conversational interaction, interlocutors are guided by certain rules, which help to uphold the Cooperative Principle and thus prevent breakdown in communication.

\section{Violating a Maxim}

Grice (1975) defines 'violation' as the unostentatious non-observance of a maxim. He points out that if a speaker violates a maxim, he or she "will be liable to mislead" (1975: 49). The unostentatious violation of a maxim generates intentionally misleading implicature.

Thomas (1995: 74) notes, "Pragmatically misleading (or potentially pragmatically misleading) utterances of this sort are regularly encountered in certain activity types such as trials, parliamentary speeches and arguments. So regularly do they occur, in fact, that they could be seen as the norm for this type of interaction, and be interpreted in that light by participants."

\section{Opting out of a Maxim}

Grice (1975) points out that a speaker 'opts out' of observing a maxim by indicating unwillingness to cooperate as the maxim requires. Thomas (1995: $74-75)$ notes that "examples of opting out occur frequently in public life, when the speaker cannot, perhaps for legal or ethnic reasons, reply in the way normally expected. On the other hand, the speaker wishes to avoid generating a false implicature or appearing uncooperative. Examples of such cases could include a priest, counselor or even an investigative journalist refusing to relay information given in confidence, or a police officer refusing to release the name of an accident victim, until the victim's relatives have been informed."

\section{Infringing a Maxim}

Grice (1975) points out that a speaker 'infringes' a maxim when he, with no intention of generating an implicature and with no intention of deceiving, fails to observe a maxim. Thomas (1995: 74) notes "the non-observance stems from imperfect linguistic performance rather than from any desire on the part of the speakers to generate a conversational implicature." He also highlights that instances of infringing a maxim can be generated by foreign speakers or children who lack full mastery of the language. Moreover, Thomas (ibid) points out that adult native 
speakers can infringe maxims when their speaking (or writing) performance is somehow impaired due to drunkenness, excitement or simply because the speaker is constitutionally incapable of speaking clearly.

Furthermore, apart from having an imperfect linguistic performance, other factors that could make speakers to infringe the maxims could be cognitive impairment, nervousness and lack of knowledge of the topic (Hanifah, 2013: 138).

Interestingly, there had been earlier studies on infringing the maxims, some of which depict infringements used in conversations (Osunbade and Adeniji, 2014), as well as in comic strips (Ambarsari, 2016). Nevertheless, in infringing the maxims, the speaker or writer unintentionally fails to observe the maxims due to inadequate capabilities and weak comprehension of the language. Essentially, it is this type of non-observance of the maxims that is the concern of this study, with focus on the instances of infringements of the Gricean maxims contained in some precautionary inscriptions on some medicine packets.

\section{RESEARCH METHOD}

The method of this research is qualitative and its paradigm is interpretive because it interprets and decodes all aspects of infringements contained in the inscriptions on some medicine packets, being the data for the study. The data were collected from some packets of medicine sold in some pharmacy shops in Lagos, Nigeria.

In the interpretive paradigm, the researcher opts for content analysis for identifying the infringed maxims contained in the precautionary inscriptions on the medicine packets. In the content analysis, the data are examined and interpreted in order to elicit meaning, obtain comprehension, and eliminate complexities from the texts, to enhance uncomplicated interpretation of the precautionary inscriptions on the medicine packets (Bowen, 2009; Baig et al. 2021).

In this connection, content analysis was conducted in which the data were interpreted with relevance to the objective of the study. The precautionary inscriptions were examined in the light of the observance of the Gricean maxims and the cases of non-observance, particularly, the cases of infringements, were detected. However, recommendations to resolving the cases of infringements were also provided in the discussion.

\section{DATA ANALYSIS}

This section deals with an analysis of some extracts of precautionary inscriptions on some medicine packets, with the objective to examine the cases of infringements of the Gricean maxims. Both the target inscriptions and their co-texts are presented for the analysis. The analysis is categorized based on the classes of the maxims, as discussed below. 


\section{Infringement of the Maxim of Quantity}

In the process of observing the code of brevity while passing information, certain essential information is left out in some precautionary inscriptions. This omission usually creates ambiguity, thus encumbering the reader with the task to figure out the appropriate meaning of the inscription. Below are instances of such cases of lack of adequate information, which thereby infringe the maxim of quantity.

\section{Dr. Meyer's \\ VITAMIN \\ B-COMPLEX \\ HIGH POTENCY \\ Store below 30c. \\ Keep away from light.}

The precautionary inscriptions above are contained on the packet of Dr. Meyer's Vitamin B-Complex High Potency. However, the inscription: "Keep away from light", infringes the Gricean maxim of quantity, by not providing adequate information on the referent "light". What kind of 'light' does the writer refer to? Is it light from the sun or from electricity? The reader is left to infer what kind of 'light' the writer means. In this case, it is the contexts that will help the reader interpret the precaution correctly by calculating the effects the light from the sun and the light from electricity could have on the medicine, respectively. On this basis, the reader may figure out that the ultra violet rays from the sun light may adversely reduce the potency of the medicine, which is not the case with electricity. Thus, the reader will interpret the precaution to mean that the medicine should be kept away from direct light from the sun, in order to retain the potency of the medicine. This interpretation could only be realized through deductions, whereby the reader, on noticing the lack of adequate information concerning the referent 'light', could resort to the contexts to make sense of the precaution, in spite of the inadequate information it contains. However, the inadequate information that the precaution contains was intended neither to generate any implicature nor to deceive the reader, because such actions are not expected of medicine producers, who will not toy with lives; rather it is a case of infringing the maxim of quantity, through an unintentional lack of adequate information. Nevertheless, this precautionary inscription could be adjusted as follows: 'Keep this medicine away from direct sunlight'.

\section{GESTID}

\section{SUSPENSION}

Store protected from light.

Keep the bottle tightly closed.

Keep all medicines out of the reach of children. 
The precautionary inscriptions above are contained on the packet of Gestid Suspension. Nevertheless, the inscription: "Keep all medicines out of the reach of children", infringes the maxim of quantity by not providing any justification for the directive. Across the globe, children are generally seen as inquisitive and curious, without being conscious of danger. These traits predispose children to much risk, because they may want to try out whatever they discover. Therefore, this precaution requires stipulating that adults should not endanger the lives of children by exposing drugs to them; rather they should carefully keep all medicines away from the contact of children, in order not to stir up the curiosity of children to ingest the drugs, which could be very risky. In this connection, this precautionary inscription could be adjusted as follows: 'To avoid risk, keep all medicines out of the reach of children'.

\section{PRIMPEX}

Co-trimoxazole

Paediatric Suspension

Keep all medicines out of the reach of children.

Protect from light.

\section{Shake well before administration.}

The above precautionary inscriptions are contained on the packet of Primpex Cotrimoxazole. However, the inscription: "Shake well before administration" infringes both the Gricean maxim of quantity and the maxim of manner, respectively. The maxim of quantity was infringed by not providing adequate information on what to "shake". Is it the patient that should shake before drinking the medicine, or just the bottle that should be shaken, or the liquid content in the bottle that should be shaken? It is the contexts that will help the reader deduce the direction of the word "shake". Through deductions, the reader will infer that what the patient needs to shake well is the liquid content. Thus, despite the infringement, the reader will interpret the direction of the word "shake" to be on the liquid content, which needs to be shaken, to blend well, for higher efficacy in treating the patient. On the other hand, the maxim of manner was infringed by being obscure through lexical complexity reflected in the word: "administration", which should be replaced with the simpler alternative word: 'use'. In this regard, the precautionary inscription could be adjusted as follows: 'Shake the liquid content well before use'.

\section{Infringement of the Maxim of Relation}

The use of general terms that are remotely connected with the message being conveyed creates vagueness in the text. This lack of use of specific lexical items that are relevant to the message infringes the maxim of relation, as depicted in the examples below: 


\section{CHLORAMPHENICOL}

"MCA"

\section{EYE DROPS}

\section{FOR EXTERNAL USE ONLY}

The above precautionary inscription is contained on the packet of Chloramphenicol "MCA" Eye Drops. In this precaution: "For External Use Only", the Gricean maxim of relation is infringed by the use of the lexical item "external", which refers to things situated 'outside'. It is only a resort to contexts that will help the reader deduce the relation between the lexical item "external" and the medication, by observing that eye drops could only be applied on the eye, which is located on the outer part of the human body. In addition, eye drops could be used irrespective of whether the patient is indoor or outdoor; and it is not to be ingested. To that extent, the reader will, through deductions, associate the word "external" with the outer body parts. This association will help the reader infer that the relevance of the word "external", in this case, is that the medication is meant to be used only on the eyes, whether indoor or outdoor. Thus, this precautionary inscription could be adjusted specifically as follows: 'For use only on the eyes'.

\section{CIPROTAB 500}

Each soft gelatin coated tablet (Soflet) contains:

Ciprofloxacin Hydrochloride USP

Equivalent to Ciprofloxacin 500mg

Excipients

Approved colours are used.

Dosage:

As directed by the physician.

Store below $30^{\circ} \mathrm{C}$.

Protect from direct sun light.

\section{RESPECT THE PRESCRIBED DOSES.}

The precautionary inscription above is contained on the packet of CIPROTAB 500. In the highlighted precaution: "RESPECT THE PRESCRIBED DOSES", the Gricean maxim of relation is infringed by the use of the lexical item "RESPECT", which denotes 'to regard', 'to esteem'. The word, 'RESPECT', usually refers to deference and value ascribed to human beings, such that the reader of the precaution would have to work out the relevance of 'RESPECT' in that inscription. It is only a resort to contexts that will help the reader deduce the relation between the lexical item "RESPECT" and the medical prescription, by observing that prescriptions should be valued with strict adherence, in order to prevent over dosage or under dosage of the medication. In this connection, the reader will, through deductions, associate the word "RESPECT" with the following directives: 'adhere to', 'keep to', and 'obey'. This association will help the reader infer that the relevance of the word "RESPECT", in this case, is that the prescription is meant to be 
heed to, in order for the patient to get the right result. Thus, this precautionary inscription could be adjusted as follows: 'KEEP TO THE PRESCRIBED DOSES'.

\section{Infringement of the Maxim of Manner}

In making lexical choices, complexities should be avoided as much as possible. Complexities create obscurity in the message being conveyed and thereby infringe the maxim of manner, as portrayed in the examples below.

\section{Antifungal, Antibacterial, Anti-inflammatory, and Antipruritic SKINEAL Cream \\ Keep out of reach of children. \\ Avoid contacting eyes. \\ Read package insert before using.}

The above precautionary inscriptions are contained on the packet of Skineal Cream. However, the inscription: "Read package insert before using" infringes the maxim of manner by being obscure through the expression: "package insert". Complexities must be avoided, particularly in every expression that is connected with medicines. The word 'leaflet' is a simpler and clearer alternative. Clarity of expression is necessary for one to get the full benefits of the medication. Thus, in order for the readers to get the required information that will enhance the treatment and recovery of the patient, the writers of precautionary inscriptions should avoid obscurity. To this extent, the above precautionary inscription could be adjusted as follows: 'Read enclosed leaflet before use'.

\section{AMATEM SOFTGEL FORTE}

\section{(Artemether 80mg + Lumefantrine 480mg) \\ Dosage:}

As directed by the Physician or as per the insert on the other hand, chart given below.

The precautionary inscriptions above are contained on the packet of Amatem Softgel Forte. However, the inscription: "as per the insert" infringes the maxim of manner by being obscure through the expressions: "as per", as well as, "the insert". Obscurities must be avoided, especially in every expression that is associated with medicines. The lexical items: 'as stated in', together with, 'the enclosed leaflet', respectively, are simpler and clearer substitutes. Clarity of expression is vital for one to gain sufficiently from the medication. Therefore, in order for the readers to get the required information that will quicken the treatment and recovery of the patient, the writers of precautionary inscriptions should avoid obscurity. In this connection, the above precautionary inscription could be adjusted as follows: 'As directed by the Physician or as stated in the enclosed leaflet or chart given below'. 


\section{RESULTS AND DISCUSSION}

The analyses of all the extracts above show that the precautionary inscriptions contain instances of infringements of three classes of the Gricean maxims, respectively; being the maxim of quantity, the maxim of relation and the maxim of manner. However, the infringement of the maxim of quantity was predominant. This predominance may be due to upholding the maxim of manner that advocates brevity. Nevertheless, essential information should not be compromised.

Interestingly, the maxim of quality is the only maxim that was not infringed in any precautionary inscription in our data. This result may be justified by the reason that precautionary inscriptions on medicine packets should be carefully expressed in truth so as not to jeopardize the health of the patients.

Invariably, the infringement of the Gricean maxims saddles the reader with the task of deducing the necessary information that was not provided in the precautionary inscriptions, thus, exposing the reader to the risk of wrong interpretation of the message being conveyed. Therefore, providing adequate and appropriate information is paramount in getting the right direction, and consequently, the right result from the medication.

\section{CONCLUSION}

This research has been engaged with an investigation of the cases of infringements of the maxims underlying the precautionary inscriptions on some medicine packets collected as the data for this study. The occurrences of the infringements, consequently, pose problems with arriving at correct interpretations of the precautionary inscriptions on the medicine packets. The study was also concerned with determining how the infringed precautionary inscriptions could be interpreted correctly. In this connection, the study concludes that in order to arrive at the correct interpretation of the precautionary inscriptions on medicine packets, the precautions should be couched carefully, without infringing the Gricean maxims, by avoiding complexities, obscurities, vagueness and ambiguities. The implications of this research findings for the scientific field, particularly the pharmaceutical sphere, is that infringed precautionary inscriptions could cause wrong interpretation of the message and any mistake in the readers' interpretation of the precautions could be disastrous, since the products have to do with health. Therefore, the messages contained in precautionary inscriptions should be very clear and direct. To this extent, further studies on various cases of infringements in diverse aspects of communication are strongly recommended. 
Journal of Pragmatics Research

Vol. 3, No. 2 (2021), pp.160-172

E-ISSN: $2656-8020$

Website: http://e-journal.iainsalatiga.ac.id/index.php/jopr/index

\section{REFERENCES}

Akmajian, A. et al (2012). Linguistics: An Introduction to Language and Communication. (Sixth Edition). Massachusetts: MIT Press.

Ambarsari, P. (2016). The Realization of the Conversational Maxims in the Comic Strip "The Born Loser" of The Jakarta Post. Graduate Program, English Education Department, Semarang State University

Auta, A., Shalkur, D., Banwat, S. B. and Dayom, D. W. (2011). "Readability of Malaria Medicine Information Leaflets in Nigeria”. Tropical Journal of Pharmaceutical Research, 10 (5): 631 -635 .

Baig, S., Javed, F., Siddiquah, A., and Khanam, A. (2021). "A Content Analysis of English Textbook of Punjab Textbook Board of Grade 8 in Pakistan”. In SAGE Open, April - June 2021: 1 - 8. DOI: 10.1177/2158244021102319.

Bowen, G. A. (2009). “Document Analysis as a Qualitative Research Method”. In Qualitative Research Journal, 9 (2), Article 27.

Bradley, B., Singleton, M. and Li Wan Po, A. (1994). "Readability of Patient Information Leaflets on Over-the-Counter (OTC) Medicines". Journal of Clinical Pharmacyand Therapeutics, 19: 7 - 15 .

Grice, H. P. (1975). "Logic and Conversation" In Cole, P. and Morgan, J. (eds.) Syntax and Semantics, Vol 3: Speech Acts. New York: Academic Press. Pp. 41-58.

Griffin, J. P. and Griffin, J. R. (1996).“Informing the Patient”. Journal of the Royal College of Physicians of London, 30 (2): 107 - 111.

Hanifah, I. R. (2013). “Non-Observance of Maxims in Facebook Conversation”. In Passage, 1 (2): $135-144$.

Huang, Y. (2007). Pragmatics. Oxford: Oxford University Press.

Kempson, R. (1975). Presupposition and the Delimitation of Semantics. Cambridge: Cambridge University Press. (1977). Semantic Theory. Cambridge: Cambridge University Press.

Leech, G. N. (1983). Principles of Pragmatics. London: Longman.

Levinson, S. C. (1983). Pragmatics. Cambridge: Cambridge University Press

Mbisike, R. C. (2001). "Investigating English Semantics and Pragmatics". In Fakoya, A. A. and Ogunpitan, S. A. (eds.) The English Compendium. Vols. 3 \& 4. A publication of the Department of English, Faculty of Arts, Lagos State University, Lagos, Nigeria. Pp. 167 187.

Mey, J. L. (2001). Pragmatics: An Introduction (Second Edition). Malden, Massachusetts: Blackwell Publishing. 
Osunbade, N. and Adeniji, A. (2014). "Information-based Infringements and Implicit Meanings in Conversations in Select Recent Nigerian Novels". In International Journal of Humanities and Social Science, Vol 4, No. 5(1). Pp. 144 - 151.

Sadock, J. M. (1978). “On Testing for Conversational Implicature.in Cole, P. (ed.) Syntax and Semantics, Vol. 9: Pragmatics. New York: Academic Press.

Sperber, D. and Wilson, D. (1981). "Pragmatics”. In Cognition, Vol. 10. Pp 281 - 286. Stalnaker, R. (1972). "Pragmatics”. In Davidson, D. and Harman, G. (eds.) Semantics of Natural Language. Lordrocht. Pp 380 - 397.

Stanley, J. (2000). “Context and Logical Form”. In Linguistics and Philosophy, Vol. 23. Pp 391 $-424$.

Thomas, J. (1995). Meaning in Interaction: An Introduction to Pragmatics. London: Longman.

Verschueren, J. (1999). Understanding Pragmatics. New York: Arnold.

Yule, G. (1996). Pragmatics. Oxford: Oxford University Press.

Yusuf, Y.K. and Odebunmi, A. (2011). "The Discourse of Information Leaflets of Medicines”. Ibadan Journal of English Studies, Vol. 7. Pp 21 - 39. 